\title{
Língua portuguesa: estratégias de compreensão dos enunciados fraseológicos em aulas de língua estrangeira
}

\author{
Lucia Helena Lopes de Matos \\ Universidade Federal Rural do Rio de Janeiro - UFRRJ - Brasil \\ Faculdade de Letras da Universidade do Porto - Portugal \\ Ihlmatos@yahoo.com.br
}

\begin{abstract}
Resumo
Por ser a língua incubadora da identidade e da cultura e construir significados que se deslocam afetados pela memória social, pretendemos, neste trabalho, seguindo os princípios da Semântica Cognitiva, debruçar-nos sobre as estratégias pedagógicas que facilitam a compreensão e confirmam a eficácia dos mecanismos cognitivos presentes nos aspectos metafóricos dos enunciados fraseológicos. A proposta levará em consideração os entraves das fórmulas fixas, cujas definições, geralmente, são dominadas pelos falantes nativos de forma automatizada, mas funcionam, muitas vezes, como obstáculos no aprendizado da língua adicional. Dar ao aprendente estrangeiro um sentimento de pertença e filiação ao novo idioma é fazê-lo participar de experiências imemoriais sedimentadas na cultura do povo que é mister conhecer, já que para dominar uma língua é necessário transitar na menção e no uso de seus significados. Levamos em consideração, ainda, a formação de professores de língua portuguesa envolvidos com a prática e a pesquisa na construção de um melhor desempenho de seu papel profissional.
\end{abstract}

Palavras-chave: Cognição, ensino e pesquisa, ensino de PLE, metáfora conceptual

\begin{abstract}
The present article aims to discuss the pedagogical strategies that facilitate comprehension and confirm the efficacy of the cognitive mechanisms present in the metaphorical aspects of phraseological statements, for language is seen as an incubator of identity and culture, as well as being able to construct meanings that are affected by social memory. The article will take into account the difficulties of proverbs that are automatic to native speakers, but often function as obstacles in the process of learning
\end{abstract}


MATOS, Lucia Helena Lopes de - Língua portuguesa:... Para lá da tarefa: implicar os estudantes na aprendizagem de línguas estrangeiras no ensino superior. Porto: FLUP, 2019, pp. 245-259 DOI: https://doi.org/10.21747/9789898969217/paraa13

an additional language. To give the foreign learner a sense of belonging and affiliation to the new language is to make him participate in immemorial experiences sedimented in the culture of the people that is necessary to know. In order to master a language, it is necessary to be mobile in the uses of its meanings. Furthermore, it will take into account the education (training) of Portuguese language teachers engaged in practice and research as a means of building a better performance of their role as a professional.

Keywords: Cognition, teaching and research, teaching PLE, conceptual metaphor

\section{1 - Introdução}

Ao professor não cabe dizer : 'faça como eu', mas: 'faça comigo'. O professor de natação não pode ensinar o aluno a nadar na areia fazendo-o imitar seus gestos, mas leva-o a lançar-se n'água em sua companhia para que aprenda a nadar lutando contra as ondas, fazendo o seu corpo coexistir com o corpo ondulante que o acolhe e o repele, revelando que o diálogo do aluno não se trava com o seu professor de natação, mas com a água. O diálogo do aluno é com o pensamento, com a cultura corporificada nas obras e práticas sociais e transmitidas pela linguagem e pelos gestos do professor, simples mediador. (Chauí,1980, p.39)

O texto bastante conhecido da filósofa brasileira Marilena Chauí foi escolhido como epígrafe deste trabalho por ser bastante significativo para os fins a que me proponho. Os estudos em educação e o trabalho como regente no curso de Letras apontam para a necessidade de, em turmas de formação de professores em línguas, termos uma atuação que possibilite o crescimento de nossos alunos tanto na área da transmissão do conhecimento quanto na assunção deste. Fazer com que os alunos tenham essa relação com o seu objeto de conhecimento é oferecer-lhes a possibilidade de encaminharem suas futuras aulas para a construção de práticas de ensino/aprendizagem mediados pela reflexão e pela descoberta conjunta (nós e eles), em uma parceria operativa e dinâmica, tal como sugere a professora Chauí, usando a imagem metafórica.

Hoje se defende que o conhecimento se processa na troca com o OUTRO e Marcuschi acentua que "somos seres cognitivos em um sentido muito diverso do que os demais seres vivos o são" (2003, p.240), já que os humanos, além de interagirem entre si, atribuem ao seu congênere e a si a intencionalidade em suas ações, havendo, dessa 
MATOS, Lucia Helena Lopes de - Língua portuguesa:... Para lá da tarefa: implicar os estudantes na aprendizagem de línguas estrangeiras no ensino superior. Porto: FLUP, 2019, pp. 245-259 DOI: https://doi.org/10.21747/9789898969217/paraa13

forma, entre eles, além de um processo colaborativo, a posse do legado cultural transmissível pelo aprendizado.

Como professores de Língua Portuguesa e atentos para o que pode se tornar entrave para o seu aprendizado, principalmente para aqueles que não a usam como língua materna, verificamos que a chave para a percepção dos significados está nas orientações para interpretar a realidade complexa que circula na nova prática linguageira com que os neófitos tentam se comunicar. Conhecer uma outra língua demanda esforço e uma sintonia de prontidão para as suas significâncias, já que a atribuição de sentidos vai depender da memória que se estabelece no saber discursivo armazenado nos espaços mentais dos sujeitos sociais, ou seja, nos interdiscursos que atravessam uma dada cultura que o aprendente ainda não domina.

Daí vem a pergunta que provocaria algumas reflexões com nossos alunos de Prática de Ensino: como aqueles que estão aprendendo um novo idioma agem diante das formas expressivas abonadas pelo uso? O significado não está pronto, cristalizado numa espécie de catálogo. Discursivamente os sentidos diversos se estabelecem através do que não está dito, mas implicado ou pressuposto, das formas diretas e indiretas do dizer, dos recursos pragmáticos e/ou figurados que provam que a língua não é só um código transmissor de informações, é por ela que uma cultura vive. Em algumas situações podemos usar apenas o saber linguístico nuclear por meio do qual o falante distingue uma palavra de outras. Mas e o saber extralinguístico?

Se tomarmos, por exemplo, o verbo chegare imaginarmos dois emissores, um muito jovem e outro bem idoso, em que o primeiro produza o seguinte enunciado: "Que bom que chegou a primavera!" e o segundo diga: "Que bom, cheguei à primavera!", sabemos, como falantes da língua, que estamos diante de uma única palavra com significados diferentes e que a palavra ainda pode aparecer em outros contextos discursivos como: "A conversa não chegou à cozinha", ou ainda: Eu, heim, chega pra lá, vamos mudar de assunto!!! "Ela chegou arrasando" "Nunca chegamos a um acordo". "Agora chega, não aguento mais!". O verbo chegar, então, pode realizar-se polissemicamente em nossas manifestações discursivas mais comuns, tanto em unidades lexicais metaforizadas quanto em expressões idiomáticas que trazem em sua composição significados marcados pela metáfora cuja desambiguação é, muitas vezes, esclarecida pelo contexto ("Chegar a mostarda ao nariz", "Chegar a brasa à sua sardinha"). Isto sem falar nos provérbios: (“Chega-te a boa árvore, boa sombra te cobrirá”) e sua sinonímia bíblica ("Chega-te aos bons e serás um deles" ou ainda: "Chegou a hora de pôr o cu na seringa"). 
MATOS, Lucia Helena Lopes de - Língua portuguesa:... Para lá da tarefa: implicar os estudantes na aprendizagem de línguas estrangeiras no ensino superior. Porto: FLUP, 2019, pp. 245-259 DOI: https://doi.org/10.21747/9789898969217/paraa13

Esses são exemplos diante dos quais o aprendente de PLE pode encontrar alguns impasses porque são particularidades de uso que tem sua culminância nos usos idiomáticos de expressões e enunciados proverbiais.

Por ser a língua incubadora da identidade e da cultura e construir significados que se deslocam afetados pela memória social e, segundo os princípios da Semântica Cognitiva, marcados pela experiência corpórea que adquirimos na relação com o meio físico, apontaremos caminhos pedagógicos que poderão estimular nossos alunos de Letras, ainda inexperientes na especificidade do ensino de PLE - aqui entendido em oposição a PLM - a se aprofundarem em pesquisas cujas rotinas facilitam a capacidade interpretativa do falante de uma nova língua.

\section{2 - Estratégias cognitivas no desempenho interpretativo}

Para além do aprendizado das relações intrassígnicas, o novo aprendente em qualquer língua também tem que dar conta das relações intersígnicas, ou seja, as relações cotextuais dentro do enunciado. Assim sendo, a palavra ocupa uma posição valorativa no discurso, não se descartando, porém, a noção de que o sistema oferece outras e novas possibilidades que paradigmaticamente poderiam ocupar a mesma posição e que estariam disponíveis em nosso léxico mental. Mediante relações associativas qualquer elemento da Langue pertence a uma classe em que se associa a outros elementos formando sistema: "escola', "aprendizagem”, “ensino", etc., são memorizáveis como membros da mesma classe de sentidos (classe da "educação", digamos), porque possuem uma mesma marca semântica na sua base (o sema "educação"). Apesar de, com base nessa mesma marca comum, eles se aproximarem uns aos outros, tais termos não se confundem, entretanto. Estaríamos, assim, explicando os significados sob o foco da análise linguística.

Se, por outro lado, quisermos explicar essas relações associativas por uma outra corrente teórica, a Semântica Cognitiva, podemos dizer que esses membros são organizados em nosso léxico mental por categorias com propriedades mais ou menos prototípicas, isto é, há identidades que os aproximam mais de um membro prototípico da classe e diferenças que os afastam. Deste modo, diálogo, troca, parceria seriam propriedades mais prototípicas de uma categoria de educação com um enquadre mais progressista, enquanto memorização, disciplina e autoridade seriam propriedades mais periféricas.

Não há necessariamente uma correspondência entre o mundo real e as categorias porque elas resultam das nossas representações mentais do mundo. O protótipo seria 
MATOS, Lucia Helena Lopes de - Língua portuguesa:... Para lá da tarefa: implicar os estudantes na aprendizagem de línguas estrangeiras no ensino superior. Porto: FLUP, 2019, pp. 245-259 DOI: https://doi.org/10.21747/9789898969217/paraa13

o exemplar mais representativo, aquele que compartilha mais características com os demais membros do conjunto e ao mesmo tempo essas características o distinguem de outros conjuntos de unidades classificatórias. Os limites de uma categoria a outra são difusos e sofrem a graduação dos membros periféricos que podem participar também de uma outra categoria.

A teoria do protótipo explica por que as categorias não podem ser tomadas como estruturas invariantes e justifica tanto a polissemia como a compreensão de metáforas novas que ativam nos espaços mentais um núcleo prototípico responsável pela "estabilidade estrutural que permite interpretar novos fatos através do conhecimento já existente" (Silva, 2004, p. 84). Esse princípio da Semântica Cognitiva foi a luz que precisávamos para nortear a situação particular que descrevo a seguir.

Por ser supervisora da atividade Estágio em Ensino de Português - no caso PLM, já que na minha universidade não há a modalidade PLE - fui estimulada pela demanda de duas alunas do meu grupo de pesquisa Cognição, Linguagens e Construção da Leitura, que se propuseram a dar aulas como voluntárias em um curso comunitário para sete refugiados. Inexperiente também que sou nas particularidades dessa modalidade, decidi enfrentar o novo desafio. Depois de estudarmos juntas uma bibliografia inicial, resolvemos (professora e alunas) nadar na piscina do conhecimento e montarmos uma aula interativa em que os estrangeiros atendidos tivessem que se expressar e fossem passo a passo construindo novos conhecimentos sobre a língua portuguesa. Aventureime na tarefa urgente, porque, depois de tantos anos atuando em turmas do fundamental e médio, acredito que as habilidades ler/interpretar e produzir textos orais e escritos devem ser as metas fundamentais do ensino, o que também é válido para o ensino de PLE, embora as metodologias sejam bem diferentes. Nossa meta para a busca das estratégias de compreensão sempre privilegiou o enfoque cognitivista, o que faz eco com as pesquisas de Figueiredo \& Bizarro:

Este funcionamento cognitivo constitui a variável mais relevante e de efeito mais imediato sobre a atividade linguística. Lemos em função de variáveis como as capacidades perceptivas, as atencionais, as de armazenamento e recuperação da memória, de solução de problemas e de criatividade, assim como em função dos conhecimentos que se tem do mundo. Tal realidade é válida em Língua Materna e não o deixa de ser em Língua Estrangeira, na qual se encontram reflectidos os saberes múltiplos que se possuem não só da e em L2, como também da e em L1. (1999, p. 465) 
MATOS, Lucia Helena Lopes de - Língua portuguesa:... Para lá da tarefa: implicar os estudantes na aprendizagem de línguas estrangeiras no ensino superior. Porto: FLUP, 2019, pp. 245-259 DOI: https://doi.org/10.21747/9789898969217/paraa13

Os aprendentes do nosso idioma eram quatro sírios e três venezuelanos, todos imigrantes em situação de vulnerabilidade e moradores da baixada fluminense do Rio de Janeiro, uma área de extrema carência econômica. Não possuíam ensino superior completo, mas todos haviam cursado o equivalente ao ensino médio. Não tinham ainda trabalho formal e o domínio da língua era um grande obstáculo, principalmente para os falantes do árabe. As aulas eram dadas na sala de uma igreja católica que prestava serviços assistenciais à comunidade local. Em princípio, os sete eram atendidos no mesmo horário, mas logo as nossas estudantes deram conta das diferenças e optaram por dividi-los em dois grupos separados, atendidos em horários contínuos durante uma hora em três dias na semana.

Visto que as professoras/alunas frequentam curso de Letras Português/Espanhol, sentiam-se mais à vontade no grupo dos venezuelanos, embora eu insistisse que apenas falassem português em ambos os grupos, tanto na sala de aula quanto fora dela. A dificuldade para a comunicação era relativa pois qualquer um dos envolvidos no projeto estavam no Brasil há pelo menos um ano.

As colaboradoras na pesquisa já tinham sido minhas alunas na disciplina Semântica e Estilística da Língua Portuguesa e dominavam alguns conceitos da Semântica Cognitiva, embora, para sua aplicabilidade, fosse necessária alguma revisão teórica. Repassamos conceitos-chave como a metáfora conceptual, a motivação experiencial, mapeamento entre domínio fonte e domínio alvo e esquemas imagéticos. Fizeram a leitura do livro Metáforas de la vida cotidiana de Lakoff \& Johnson, com tradução de Carmen González Marín, escolhido na versão em espanhol para impulsionar o domínio desse idioma.

O processo cognitivo é um processo mental que se traduz em conhecimento e permite ao sujeito, através da memória do já conhecido, fazer previsões, através das inferências, das pressuposições e do levantamento de hipóteses. Quando nos valemos da memória, costumamos ativar espaços mentais tanto no terreno da esfera conceitual (que concentra o pensamento metafórico e a competência metalinguística) quanto no terreno da esfera intuitiva ou arquetípica, alimentada das lembranças das vozes e textos que marcam a ideologia e a historicidade de uma dada cultura e ressoam em nossas vozes e na de outros como interdiscursos. Essas noções seriam fundamentais para alavancar a capacidade de fazer relações entre a cultura nativa e a que estavam mergulhados no presente.

Mas ainda tínhamos um outro desafio: fazer com que os imigrantes percebessem o que Ihes era inusitado na nova cultura e o que poderia ser obstáculo para uma leitura 
MATOS, Lucia Helena Lopes de - Língua portuguesa:... Para lá da tarefa: implicar os estudantes na aprendizagem de línguas estrangeiras no ensino superior. Porto: FLUP, 2019, pp. 245-259 DOI: https://doi.org/10.21747/9789898969217/paraa13

mais eficaz do seu novo quotidiano. Sabendo-se que em nossa mente as situações se apresentam como cenários, com os quais vamos nos familiarizando à medida que as assimilamos, as nossas estudantes/pesquisadoras deveriam proporcionar aos seus aprendentes uma intimidade com a nova língua ao apresentar-lhes um tipo de enunciado com um forte acento cultural, mas, ao mesmo tempo, os remetesse para as cenas que Ihes eram familiares em sua língua materna, a fim de que a particularidade do fato pudesse ser transportada para a generacidade do conceito metafórico.

Antes, porém, elas deveriam dominar a noção de que o nosso pensamento é imaginativo (corresponde a imagens), daí o pensamento ser metafórico. Essas imagens são os nossos modelos cognitivos idealizados, "ICMs", (Lakoff, 1987, pp. 68-76), ou seja, eles emolduram a nossa maneira de pensar, agir e interagir entre os membros da comunidade e se formam a partir da necessidade que temos de organizar concretamente alguns conceitos abstratos. Esse é um procedimento natural com os indivíduos que dominam um conhecimento linguístico, segundo a Semântica Cognitiva, o que pode ser comprovado tanto em L1 como em L2.

Admitindo a hipótese de ser esse caminho teórico bastante produtivo para alunos que aprendem um novo idioma, resolvemos focar, depois de cerca de quatro meses de aulas empiricamente conduzidas e com pouco sucesso, no estudo das expressões idiomáticas e dos provérbios, visto que a construção de seus significados passam quase sempre pelo viés metafórico e obedecem a uma especificidade que sempre traz dificuldade a quem não está imerso na cultura da língua alvo. Tanto os provérbios quanto as expressões idiomáticas são

...formas caracterizadas pela fixidez, polilexicalidade, idiomaticidade, fraseologização ou lexicalização e abrange um leque de expressões que vão desde o frasema (ou fraseologismo) típico até formas mais amplas, o equivalente a frases ou sentenças (e porventura, a pequenos textos: os provérbios). (Vilela, 2002, p. 219)

Somando-se a isto, segundo Figueiredo \& Figueiredo (2010, p. 161), levar o aprendente da nova língua a dominar o emprego das unidades fraseológicas a partir do domínio progressivo dos significados é levá-lo a uma autonomia comunicativa desejável. As duas pesquisadoras ainda apontam a importância de se relacionar o novo e o dado, ou seja, inter-relacionar as experiências armazenadas em seus domínios mentais com as novas situações vividas. 
MATOS, Lucia Helena Lopes de - Língua portuguesa:... Para lá da tarefa: implicar os estudantes na aprendizagem de línguas estrangeiras no ensino superior. Porto: FLUP, 2019, pp. 245-259 DOI: https://doi.org/10.21747/9789898969217/paraa13

Ademais, levamos em consideração "a particular afinidade da língua árabe com a estrutura dos provérbios", como informa Lauand (2014, p. 128) - já que os venezuelanos partilham conosco uma cultura mais ocidental - trazendo também outra informação relevante para nós:

Paul Auvray, em seu estudo sobre as línguas semíticas, analisa mais uma característica importante para entendermos os provérbios árabes: um acentuado voltar-se para o concreto (ele refere-se ao hebraico bíblico, mas sua análise é válida para as línguas semitas em geral). Naturalmente, trata-se de uma questão de ênfase, pois - insisto - este voltar-se para o concreto não é apanágio árabe ou semita. É fenômeno humano, em alguma medida presente em todas as línguas. (p. 129)

A figuratividade de alguns provérbios e também de algumas expressões idiomáticas é motivada, muitas vezes, por situações concretas que serviram para mapear conceitos abstratos num tempo e espaço sem referência. "Normalmente o significado idiomático é o resultado de um processo histórico em que o significado literal e o figurado foram se afastando progressivamente" (Vilela, 2002 p. 196). Existe, pois, uma linguagem literal que migrou para um significado figurado estereotipado, gerado a partir de uma situação de base experiencial. Combinamos, pois, que alguns fraseologismos (nem todos: alguns são interpretados via literalidade, outros não possuem vínculo motivacional) deveriam ser selecionados a partir da sua motivação literal para que o aluno de PLE pudesse ter convivência com dificuldades progressivas na língua e pudesse, também crescer na capacidade interpretativa de um novo cenário linguístico-cultural.

A partir da seleção do material, tentaríamos auxiliar os venezuelanos e os sírios, diante das dificuldades encontradas, ao fazer uma ponte entre os seus conhecimentos prévios sobre linguagem, a sua observação, ainda que incipiente, sobre a nova cultura em que transitam e a sua experiência em relação ao mundo biopsicossocial. Todos esses elementos seriam fundamentais para destacar a motivação de muitas das metáforas das expressões idiomáticas e também os esquemas imagéticos que originam muitos provérbios da língua em aprendizado. Ao perceber as generalizações, os mapeamentos entre domínios, os modelos cognitivos idealizados, o aluno iria progressivamente despertar o olhar para as sutilezas culturais veiculadas pela língua e iria construir progressivamente um modelo cognitivo de aprendizado para dar conta de outras metáforas mais elaboradas. 
MATOS, Lucia Helena Lopes de - Língua portuguesa:... Para lá da tarefa: implicar os estudantes na aprendizagem de línguas estrangeiras no ensino superior. Porto: FLUP, 2019, pp. 245-259 DOI: https://doi.org/10.21747/9789898969217/paraa13

Primeiro, planejamos eles terem contato com as expressões e provérbios com graus baixos de figuratividade ou até mesmo literais. Oferecemos as expressões: "Tomar a palavra", "Perder tempo" e os provérbios: "Antes só do que mal acompanhada", "Mais vale amigo na praça que dinheiro na caixa", "Para bom entendedor meia palavra basta", "Não faças aos outros o que não queres que façam a ti". E sugerimos atividades orais em que eles descreveriam algumas situações nas quais o encaixe desses enunciados fraseológicos houvesse relevância. Para os venezuelanos a atividade foi cumprida com dificuldades mais em formar textos orais consistentes e a tradução de uma ou outra palavra do que entender o significado global da expressão ou do provérbio e inseri-los em enunciados mais completos. Para os sírios, porém, a atividade foi mais complicada. Encontraram dificuldade com a oralidade narrativa e os textos criados por eles eram paráfrases dos provérbios, com alguma intuição do significado: "Cuidado com os inimigos", "Serve mais amigos que dinheiro", "Se entende melhor uma língua, começa dizer uma palavra e já se entende toda frase" (cremos que queriam dizer que se infere o significado), "Não faz o que não quer receber", "O bom filho não se afasta dos pais". Quanto às expressões, seus significados eram já conhecidos. Eles foram incentivados a, antes de executarem o exercício, trocarem sugestões entre si para que deixassem aflorar os conhecimentos da língua materna.

$\mathrm{Na}$ atividade seguinte, as duas fizeram uma pequena dramatização improvisada usando as expressões com o verbo CHEGAR para explicar a sua polissemia. Nesse momento elas tentaram explicar a diferença entre os graus de literalidade e figuratividade. Mostraram que essa classificação estabelece num continuum as palavras armazenadas em nosso leque mental do menos figurado ou rotineiro ao mais inusitado. Mas mesmo aquelas metáforas mais estranhas estão ligadas a um conceito metafórico genérico o que facilita a sua desambiguação.

Se levarmos em consideração expressões com o verbo CHEGAR perceberemos que todas remetem a movimento de repulsão (Chega pra lá / Agora chega!) ou de atração (Chega-te aos bons e serás um deles), movimento em direção ao destino (Chegou a uma conclusão / A conversa não chegou à cozinha), movimento de proximidade com o alvo (Chegou a brasa à sua sardinha). Todas indicam a metáfora genérica EVENTOS SÃO MOVIMENTOS.

E vieram mais exemplos: Chegou a primavera (movimento em percurso temporal), chegar às vias de fato (movimento possui limites), chegou aos meus ouvidos (movimento de aproximação). 
MATOS, Lucia Helena Lopes de - Língua portuguesa:... Para lá da tarefa: implicar os estudantes na aprendizagem de línguas estrangeiras no ensino superior. Porto: FLUP, 2019, pp. 245-259 DOI: https://doi.org/10.21747/9789898969217/paraa13

Como o verbo estava inserido em um contexto, os aprendentes inferiram algumas expressões, mas ficaram relutantes, principalmente com o significado dos provérbios. Tanto um grupo quanto outro disse que o "movimento em direção ao destino" Ihes era mais comum e deram como exemplo: "Cheguei a casa", "cheguei ao fim da estrada", "cheguei ao trabalho" etc.

As expressões idiomáticas não são enunciados completos, algumas são mais difíceis de resgatar sua motivação (outras são claramente motivadas) e vão estar, normalmente, inseridas em um contexto de fala ou escrita, o que facilita a ativação das inferências no processo interpretativo do aluno de PLE, por outro lado são praticamente todas metaforizadas. Os provérbios têm maior fixidez, podem ser literais ou metafóricos e, tanto estes quanto as expressões são fórmulas enunciativas que podem estar condicionadas a uma interpretação figurada pelos esquemas imagéticos que refletem os estereótipos de uma dada cultura. De seguida, são apresentados alguns exemplos.

Tapar o sol com a peneira: a imagem remete a um cenário fadado ao insucesso, afinal a dedução é de que pelos trançados da peneira, inevitavelmente, o sol passaria. Essa expressão com ou sem contexto é de fácil entendimento e foi apresentada para realçar a motivação metafórica que em seu viés genérico aponta para a tentativa de esconder o impossível.

Casa de ferreiro, espeto de pau: há nesse provérbio uma imagem concreta que traz a inversão de uma expectativa, conduzindo à inferência de seu significado. Houve uma frustração na escolha desse provérbio. Elas precisaram na aula seguinte concretizar com objetos e desenhos a metáfora imagética do provérbio.

Cada macaco no seu galho: a imagem concreta já aponta para a harmonização do ambiente, o que aproxima o interpretante do significado de que cada um deve estar no lugar que, ou fazer aquilo que, Ihe compete. Não houve problemas na leitura do significado do provérbio.

Com a corda no pescoço: esta expressão refere-se a alguém que esteja em uma situação aflitiva. A imagem evoca as cenas de enforcamento, muito comum na Idade Média, - e talvez ainda hoje em algumas civilizações - para executar pessoas e sua força é presente no imaginário humano. Não houve entraves para a inferência do significado. 
A conversa não chegou à cozinha: observou-se que essa expressão é muito carregada de referências culturais. A imagem remete os brasileiros a um tempo em que serviçais se reuniam para cozinhar e a conversa rolava à solta, logo era o lugar ideal da casa para se conversar. Se a conversa não chegou lá é porque a conversa não é relevante, é sem importância ou, por extensão, inadequada. E ainda: ... a conversa não é da sua conta ou não the interessa. Hoje, que o prazer de cozinhar está sendo resgatado, em muitas construções modernas não há mais paredes separando a cozinha da sala. Aqui também as professoras/alunas precisaram se valer da narrativa histórica brasileira para explicar a sua vinculação cultural e fazer analogia com os hábitos mais modernos.

De noite todos os gatos são pardos: a imagem remete literalmente para a dificuldade na distinção, sendo, portanto, alargado na figuratividade para explicar situações em que os elementos perdem suas particularidades. Aqui os aprendentes precisaram ser instigados para sair do particular para o genérico e inferirem o significado metafórico.

Estar para (pra) baixo : significa não estar bem, estar triste ou deprimido. Essa expressão tem origem na metáfora orientacional RUIM É PARA BAIXO em oposição a BOM É PARA CIMA cuja motivação possui uma base física corpóreo-experiencial, ou seja, nossa postura física é mais ereta quando estamos bem de saúde, alegres e mais caída quando estamos doentes ou deprimidos. Essa orientação espacial é bastante produtiva para expressar um raciocínio abstrato através de metáforas baseadas em esquemas imagéticos (Silva, 2003, p. 24). As docentes apresentaram-lhes outros exemplos: Chegar ao fundo do poço. Alto comando. Por cima da situação. Levantar o astral. Descer nas pesquisas. A nossa intenção era que os aprendentes de LP percebessem a motivação que há por trás desses esquemas imagéticos.

Águas passadas não movem moinhos: como os moinhos só se movimentam impulsionados pelas águas que estão a passar e não pelas que já passaram, a imagem motiva a inferência do ensinamento que o provérbio quer passar: não se deve ficar preso ao passado. Não foi difícil para os dois grupos. Aqui as pesquisadoras trouxeram um outro provérbio que dialoga com o significado deste: Não adianta chorar sobre o leite derramado e pediram que eles inferissem o significado. Facilmente deduziram que não se deve lamentar o que passou. 
MATOS, Lucia Helena Lopes de - Língua portuguesa:... Para lá da tarefa: implicar os estudantes na aprendizagem de línguas estrangeiras no ensino superior. Porto: FLUP, 2019, pp. 245-259 DOI: https://doi.org/10.21747/9789898969217/paraa13

Dor de cotovelo: sofrimento por traição ou inveja. Pedimos aos próprios estrangeiros que deduzissem a motivação dessa expressão e apenas um venezuelano arriscou a possibilidade de estar ligada ao fato de que, ao se magoar essa região, sente-se uma dor aguda e forte, como se levasse um choque elétrico, o que possivelmente tenha inspirado a criação da expressão. O nosso objetivo era o exercício da inferência do significado muito mais do que o acerto da resposta, até porque não se tem a certeza total da origem da expressão.

Roupa suja lava-se em casa: essa imagem concreta não levou os alunos a inferirem facilmente a abstração metafórica. O significado de que se deve preservar os íntimos da exposição pública negativa teve que ser conduzida e praticamente revelada pelas alunas/pesquisadoras.

Gato escaldado tem medo de água fria: a imagem do gato - que já não gosta de água - ter tido a experiência de se queimar com a água quente e, a partir de então, fugir ainda mais da água, mesmo que esteja fria, remete para uma outra isotopia, a dos humanos. O conector isotópico que é comum às duas isotopias é a palavra "medo". Não foi difícil aos dois grupos passar da cena concreta para a abstração que faz alusão ao cuidado que se tem de não repetir experiências negativas vividas anteriormente.

Pisar na bola: significa cometer algum deslize. Ao se pisar em uma bola, normalmente perde-se o equilíbrio e cai-se, mas chegar a este significado com base na imagem não foi tarefa fácil. Precisou da ajuda das alunas/professoras que inseriram a expressão em um texto criado de improviso.

Tal pai, tal filho: embora esse provérbio seja interpretado via literalidade, interessava-nos mostrar-Ihes que havia provérbios em suas línguas que circulavam no mesmo campo semântico. As alunas/pesquisadoras apresentaram aos sírios: "Pai dele, alho; mãe, cebola. Como pode ele cheirar bem?" e aos venezuelanos: "Hijo de gato caza ratón". Esse era o ensejo para apresentar-Ihes a próxima tarefa. Foi pedido que pesquisassem na internet provérbios de suas línguas que tivessem semelhança significativa com provérbios de língua portuguesa. Aqui, tanto os venezuelanos quanto os sírio não se saíram mal. 
MATOS, Lucia Helena Lopes de - Língua portuguesa:... Para lá da tarefa: implicar os estudantes na aprendizagem de línguas estrangeiras no ensino superior. Porto: FLUP, 2019, pp. 245-259

DOI: https://doi.org/10.21747/9789898969217/paraa13

Cair a ficha: expressão advém de um mecanismo dos telefones públicos brasileiros que passavam a funcionar no momento que se inseria uma ficha de metal. Abria-se, então, a linha para se processar a comunicação. Por extensão, a expressão veio a significar a (im)possibilidade humana de compreender algo. Foi difícil a apreensão da metáfora por estar muito carregada de aspectos culturais específicos da comunidade brasileira. Assim como essa, há várias outras que vão surgir à medida que as aulas progridem, mas agora com muito mais possibilidade de autonomia por parte dos aprendentes estrangeiros.

\section{3 - Conclusão}

Avaliamos o trabalho que durou cerca de quatro semanas e conversamos sobre os erros e acertos. Concordamos que precisaríamos nos aprofundar nos estudos de PLE e nos sentimos muito incentivadas a procurar caminhos para o aperfeiçoamento. A consequência é eu estar aqui na FLUP a fazer Pós doutoramento com interesse redobrado na área de ensino de Língua Portuguesa Estrangeira. Espero plantar essa semente no curso de letras da UFRRJ e deixá-la florescer para que colegas venham a se interessar pela modalidade e possamos ampliar os horizontes profissionais dos alunos que estão a licenciar-se em nossa instituição.

As alunas/pesquisadoras gostaram do resultado, motivaram-se a estudar mais sobre PLE e já se inscreveram em um curso a distância. Pediram-me material para conhecer mais sobre os fraseologismos da língua. Agora pesquisam crónicas brasileiras para que possam trabalhar os enunciados fraseológicos a partir de material autêntico. Todo esse movimento confirma as nossas expectativas de que a pesquisa e a prática pedagógica se retroalimentam.

A leitura de textos teóricos e a discussão de nossas ações muito ajudou a superar as dificuldades e deu-nos um norte para planejarmos exercícios e trabalharmos com expressões idiomáticas e provérbios tendo como foco a metáfora com valor cognitivo, recurso que acreditamos ser uma estratégia para a compreensão de textos de diferentes gêneros. A metáfora, porém, se mostrou produtiva em nossas análises porque nunca deixamos de associá-la à sua função pragmática.

Esse também foi um projeto que revelou, por meio da experiência, a importância da cultura na formação das línguas e de seus significados. Levou à comprovação de que é uma tendência das línguas expressar conceitos abstratos usando a concretude dos esquemas imagéticos. Um fenômeno reconhecido pelos aprendentes de nosso idioma quando compararam nossos enunciados fraseológicos com os de sua origem. 
MATOS, Lucia Helena Lopes de - Língua portuguesa:... Para lá da tarefa: implicar os estudantes na aprendizagem de línguas estrangeiras no ensino superior. Porto: FLUP, 2019, pp. 245-259 DOI: https://doi.org/10.21747/9789898969217/paraa13

Comprovamos, ainda, que é na construção do conhecimento com a mediação colaborativa do professor (também aprendiz) que vamos aos poucos abandonando as práticas pedagógicas autoritárias a fim de edificarmos uma relação mais reflexiva e autoral nos estudos das línguas e das culturas que veiculam.

\section{Referências bibliográficas}

Chauí, M. (1980). Ideologia e Educação. Educação \& Sociedade, Campinas, ano II, n. $5,24-40$.

Dias, I. S. (2010). Competências em educação: conceito e significado pedagógico. Revista Semestral da Associação de Psicologia Escolar e Educacional 14 (1), 73-78.

Figueiredo, O. \& Bizarro, R. (1999). A leitura como um processo cognitivo. Pinto, M. G; Veloso, J. \& Maia. B. Psycholinguistics on the threshold of the year 2000 Proceedings of the 5th International Congress of the International Society of Applied Psycholinguistics. Faculdade de Letras da Universidade do Porto, 465-470.

Figueiredo, O \& Figueiredo, B. E. de (2010). Unidades fraseológicas no ensino de PLE. Perspectiva Intercultural. Limite - Revista de Estudios Portugueses y de la Lusofonia, $n^{\circ}$ 4, 155-166.

Lakoff, G. \& Johnson, M. (1987). Women, Fire, and Dangerous Things. What Categories Reveal about the Mind. Chicago: The University of Chicago Press.

Lakoff, G. \& Johnson, M. (2001). Metáforas de la vida cotidiana. 5a ed. Madrid: Cátedra. Colección Teorema.

Lauand, J. (2014). Cem provérbios da tradição árabe. Notandum 35/36. Chie Hirose \& Roberto C. G. Castro, 127-140. Disponível em www.hottopos.com/notand35

Lima, A. de (2009). Metáfora e cognição. Recife: Ed. Universitária da UFPE.

Marcuschi, L. A. (2003). Atividades de referenciação e categorização na produção de sentido. Feltes, H. P. de M. (org.) Produção de sentido: estudos transdisciplinares. São Paulo: Annablume; Porto Alegre: Nova Prova; Caxias do Sul: Educs.

Matos, L. H. L. de (2006). A metáfora e a intertextualidade: uma realização multicultural na Língua Portuguesa, Universidade do Estado do Rio de Janeiro.

Silva, A. S. da (2003). O poder cognitivo da metáfora e da metonímia. Revista Portuguesa de Humanidades 7. Faculdade de Filosofia da Universidade Católica Portuguesa, 13-75.

Silva, A. S. (2004). Protótipos, imagens e metáforas, ou o experiencialismo da linguagem e do pensamento. Dinis, A. \& Curado, J. M. (org.). Consciência e Cognição. Braga: Faculdade de Filosofia de Braga - Publicações, 79-96. 
MATOS, Lucia Helena Lopes de - Língua portuguesa:... Para lá da tarefa: implicar os estudantes na aprendizagem de línguas estrangeiras no ensino superior. Porto: FLUP, 2019, pp. 245-259 DOI: https://doi.org/10.21747/9789898969217/paraa13

Urbano, H. (2008). Da Fala para a escrita: o caso de provérbios e expressões populares. Revista Investigações, 21, 2, 31-56. Disponível em: https://periodicosufpe.br/revista/INV/ article/view/1417/1096. Acesso em: 12/11/18.

Vilela, M. (2002). Metáforas do nosso tempo. Coimbra: Livraria Almedina. 